\title{
El difícil cambio hacia el Frente Popular: la Tercera Conferencia de Partidos Comunistas Latinoamericanos en Moscú (1934)
}

\author{
The difficult change to the Popular Front: The III-th conference of the Latin \\ American communist parties in Moscow, October, 1934
}

\author{
Andrey Schelchkov ${ }^{*}$
}

\begin{abstract}
Resumen: En la historia del movimiento comunista, la Tercera Conferencia de los Partidos Comunistas Latinoamericanos en 1934 sigue siendo un campo por explorar. Con ella concluye el "tercer periodo" y se inicia el cambio hacia la política de los frentes populares. En virtud de sus resultados, no pudo justificar a los ojos de los directivos de la Internacional Comunista el rol que le habían atribuido: elaborar nueva táctica para los partidos de la región, preparando así las resoluciones históricas del VII congreso de la Comintern. Las resistencias abiertas y reservadas de los líderes comunistas latinoamericanos contradecían a la nueva línea de la Internacional, lo que provocó el olvido y omisión de esta conferencia en la historia oficial de la IC. La mayor resistencia a la línea del Frente Popular la opuso la burocracia regional del Secretariado Sudamericano y del PC argentino, que perdieron sus posiciones políticas en la IC gracias a la proclamada mayor autonomía de los partidos nacionales. Este escrito está dedicado a este episodio poco conocido de la historia cominterniana en América Latina.
\end{abstract}

Palabras Claves: Tercera conferencia de los partidos comunistas, Frente Popular, Comintern, nacional-reformismo, Rodolfo Ghioldi, Luis Carlos Prestes

\begin{abstract}
In the history of the Latin American's Communist movement, the 3rd Conference of the Communist Parties of Latin America, which took place in 1935, remains a field to be explored. Destined to be a political event that would conclude the policies and dogmas of the "third period" and mark the beginning of changes of the Comintern towards the policy of the Popular Front, based on its results it could not justify in the eyes of the directors of the International the role that had been assigned to it: elaborate new tactics for the parties of the region and prepare the historical resolutions of the VII Congress of the Comintern. The open and reserved resistances of the Latin American communist leaders contradicted the new line of the International, conditioning the oblivion and omission of this conference in the official history of the Comintern. The cominternian bureaucracy of the regional apparatus and consequently of the Argentine Communist Party, threatened by national parties with greater autonomy, offered a strong resistance to the Popular Front. This article is dedicated to this little-known episode of the Comintern history in Latin America.
\end{abstract}

\footnotetext{
* Dr. en historia, investigador del Instituto de la Historia Universal de la Academia de los Ciencias de Rusia,
} sch2000@mail.ru Investigator of the Institute of World History of the Russian Academy of Science. 
Keywords: 3-rd conference of the Latin-American communist parties, Popular Front, national-reformism, Rodolfo Ghioldi, Luis Carlos Prestes.

Recibido: 2 febrero 2018

Aceptado: 5 abril 2018

La Revolución rusa dio origen al movimiento comunista internacional, que jugó un papel considerable en la historia del siglo XX. Como sostiene Enzo Traverso, para este movimiento la idea de la revolución daba forma a una visión especial del futuro y, en este sentido, la historia del comunismo es una «memoria del futuro» ${ }^{1}$. Especialmente en el continente latinoamericano, la revolución era tema principal en los análisis históricos, pero también ocupaba un lugar de privilegio en las imágenes que se construían sobre el futuro. Al cambiar los protagonistas del proceso revolucionario en los nuevos periodos históricos, la experiencia del pasado, la visión del futuro de los revolucionarios de entonces, sigue atrayendo la atención no solamente de los historiadores, sino también, de los actores sociales actuales. Hoy en día, la historia de los movimientos de la izquierda latinoamericana y del movimiento comunista sigue estando en el centro de los estudios sociales y políticos del siglo XX.

La III Internacional (Comintern) o Internacional Comunista (IC) fue fundada en 1919 como un partido mundial de la revolución proletaria, es decir, su visión remitía a la necesidad de una revolución socialista a escala global. Esta idea no fue una innovación teórica sino el resultado de la teoría y de la táctica de la socialdemocracia internacional en el periodo anterior a la Gran Guerra, cuando términos como "política mundial", "economía mundial" y luego "guerra mundial", formaron parte de las visiones políticas europeas. Esta idea fue expresada nítidamente por Rosa Luxemburgo como "socialismo o regresión a la barbarie". El repliegue hacia la tesis de la dirección soviética post-leninista de la construcción del socialismo en un solo país, fue un viraje en la política del comunismo internacional que tomó mayor cuerpo y basamento con la línea de "unidad democrática y antifascista" de los Frentes Populares, a mediados de la década de 1930, lo que provocó desajustes y desequilibrios en un movimiento formado sobre una base ideológica diferente.

Con este viraje se daba primacía a la construcción del socialismo en la Unión de Repúblicas Socialistas Soviéticas (URSS), subordinando a ello las demás tareas del movimiento comunista internacional. Las circunstancias internacionales de la década de 1930, con la amenaza del fascismo en Europa y la consolidación del imperio burocrático estalinista, obligó a los directivos soviéticos a revisar las tácticas anteriores y a buscar aliados fuera de la lucha revolucionaria proletaria, lo que dio origen a la idea del Frente Popular, reflejo y espejismo, a escala nacional, de la alianza de la URSS con los países burgueses para enfrentar la avalancha ultraderechista del fascismo. El paso siguiente y lógico sería la liquidación de la IC, lo que provocó resistencias en el seno de la burocracia

\footnotetext{
${ }^{1}$ Traverso E. Memoria del futuro. Sobre melancolía de izquierda. // Nueva Sociedad. No. 268. Marzo-abril,
} 2017. P. 154 
cominterniana. Como sostiene Fernando Claudin, los cambios tácticos radicales en la política de la IC, formalmente anunciados en su VII Congreso y discutidos en el aparato en el período anterior, eran "una fase preparatoria, dentro de la 'nueva orientación táctica', utilizando el aparato de la IC para vencer las resistencias que pudiesen surgir en algunas secciones nacionales" frente a la próxima disolución de la $\mathrm{IC}^{2}$.

En la historia cominterniana, el periodo anterior al VII Congreso y al viraje táctico de los partidos comunistas hacia los frentes populares, carece de estudios sistemáticos para los partidos latinoamericanos, periodo en que tuvieron lugar importantes eventos en el movimiento comunista regional vinculados con el cambio de las políticas ultraizquierdistas del "tercer periodo" 3 al Frente Popular. Este cambio estuvo completamente subordinado a las decisiones del Partido Comunista de la Unión Soviética (PCUS) y no a las discusiones dentro de la IC, ya que la "bolchevización" realizada en el período anterior aniquiló por completo toda posibilidad de autonomía y de libre discusión interna en los partidos nacionales. Sin embargo, era necesario cumplir con el procedimiento burocrático de discusión y adaptación de las tácticas y consignas propuestas desde el Olimpo moscovita. Como indicó Eric Hobsbawm, "la lealtad a Moscú dejó de depender de la aprobación de su línea, así que se convirtió en una necesidad operativa... la mayoría de los comunistas trató de racionalizar esto probándose a sí mismo que Moscú tenía siempre razón"4.

Varias reuniones y consultas en el Secretariado Latinoamericano (SLA) y, luego, la Tercera Conferencia de Partidos Comunistas Latinoamericanos, fueron importantes pasos preparativos en la organización del VII Congreso y en la adaptación al nuevo curso de la IC. Sin embargo, en los estudios cominternianos esta conferencia es casi completamente desconocida. Lo que se explica por su carácter confidencial, por un lado, y la no publicación de sus resoluciones, por el otro. La historiografía comunista oficial nunca se refería a esta conferencia a pesar de su evidente importancia para todo el movimiento.

Por su parte, la historiografía comunista de los diferentes países del continente se concentró en el enfoque nacional del cambio de línea hacia Frente Popular y presentó este cambio como un signo divino, como Deus ex machina proveniente de la capital mundial comunista, ajustándolo a la tradición y cultura política nacionales. Este texto pretende demostrar que los comunistas latinoamericanos, con pocas excepciones, como fue el caso de Chile, no abrazaron con entusiasmo el cambio político de la IC que estaba tomando cuerpo en 1934, cuando se reunió la Tercera Conferencia e, incluso, fue resistido por las direcciones de algunos de los partidos más numerosos, como el argentino y el mexicano. La Tercera Conferencia revela las contradicciones internas en el movimiento comunista latinoamericano, opacadas más tarde cuando se aprobaron las resoluciones del VII

\footnotetext{
${ }^{2}$ Claudin F. La Crisis del movimiento comunista, p.58

http://www.marxistarkiv.se/espanol/komintern/claudin-crisis_del_movimiento_vol1.pdf 15.12.17

${ }^{3}$ Concepto teórico aprobado en el VI Congreso de la IC que consistió en anunciar el advenimiento de la última crisis del capitalismo y los umbrales de la revolución socialista. Tácticamente significó un obrerismo a secas, sectarismo político y la lucha contra la social-democracia (tildada de social-fascista) como enemigo principal, realizando, paralelamente, la "bolchevización" de los partidos, o sea, su homogeneización de acuerdo a las directivas de Moscú, además de la purga de los "intelectuales pequeño-burgueses” y de todo el bagaje teórico-político local o heterogéneo, incompatible con el estalinismo predominante.

${ }^{4}$ Hobsbawm E. Revolucionarios. P.15-16.
} 
Congreso sobre le Frente Popular y nueva política de la IC; en ese entonces, oponerse a la línea oficial era pasar al campo enemigo.

Los procesos que aquí proponemos analizar tuvieron su base y origen en la política interna y externa de la URSS, y que se translució en las posiciones de los partidos comunistas locales. Muy frecuentemente, esto ocurría sin análisis de las realidades nacionales, lo que a menudo llevaba al fracaso a los Partidos Comunistas, con algunos raros casos de éxito. En cierto sentido, el movimiento comunista en los años 20 y 30 fue una "comunidad imaginada" tanto en su forma como en su contenido, más vinculada con los procesos que se desarrollaban en la URSS que en sus propios países. Esta es una de las razones por las que analizamos el devenir de la táctica frentepopulista sin entrar en detalles de las políticas de los partidos comunistas nacionales.

A pesar de que la historiografía sobre el comunismo latinoamericano ha tenido avances en los últimos años, sobre todo tras acceder a los archivos de la IC en Moscú (abiertos a principios de la década de 1990), la Tercera conferencia estuvo por mucho tiempo fuera del interés de los investigadores. Existen algunos artículos publicados por los rusos Igor Yanchuk, y Victor y Lazar Jeifets, cuyo trabajo es pionero en el estudio de este evento ${ }^{5}$. Yanchuk publicó algunos documentos de la Conferencia en las páginas del Almanaque Histórico Latinoamericano, sin poder publicarlo todo por razones linguísticas de los originales. Obviamente, el tema tiene aristas pendientes de indagación y su abordaje sirve para completar una página importante de la historia latinoamericana de la IC.

En el archivo de la Comintern (RGASPI) solamente se conservan las estenografías de las ponencias y de las intervenciones de los delegados, pero traducidas al ruso. Casi no hay documentos originales en el idioma en que se daban. Esas son las fuentes disponibles para la reconstrucción de la reunión, por lo que, en este trabajo, todas las citas corresponden a esas traducciones que, en su mayor parte, son de muy mala calidad. Esta dificultad estuvo, sin duda, entre las causas de la imposibilidad de publicar hasta hoy esos materiales, pese a los varios esfuerzos de hacerlo.

\section{Preparativos de la Tercera Conferencia}

Desde principios de 1934 hasta el VII Congreso de la IC (agosto de 1935), el movimiento comunista vivió un período de transición atravesado por la confusión, el temor, los contratiempos internos y las luchas intestinas en el aparato de la Internacional. Fue en ese contexto que se dio paso a la nueva táctica, abandonándose los baluartes del "tercer período". El investigador ruso Iakov Drabkin subrayó que el cambio estratégico hacia la nueva línea del VII Congreso "se preparaba hacía tiempo y con muchas dificultades ya que requería superar muchos estereotipos enraizados en el movimiento comunista y en su cúpula dirigente", y el cambio "no fue tan decisivo, como al principio le pareció a

\footnotetext{
5 Jefets L.S., Jeifets L.S. La izquierda latinoamericana en camino hacia el Frente Popular, los años 30 del siglo XX// Latinskaya Amerika. Moscú, ILA RAN. No.5. 2014 (en ruso); Yanchuk I.I. En camino hacia el Frente Popular: 3-ra conferencia de los comunistas latinoamericanos de 1934. // Latinoamerikanskiy istoricheskiy almanakh. Moscú, IVI RAN. №3. 2002 (en ruso).
} 
muchos"6. En los documentos de la IC vemos una combinación extravagante de tesis contradictorias sobre la lucha intransigente contra el nacional-reformismo y la "vendida" socialdemocracia, con ideas sobre la necesidad de un frente (lo más amplio posible) contra la amenaza del fascismo; una mezcla sobre asalto al poder por vía armada, y consignas en apoyo a la democracia burguesa en su confrontación con el fascismo.

En febrero de 1934, en la sede de la Comintern, se tomó la decisión de convocar el VII Congreso para el otoño del mismo año. En mayo se redactó la agenda del Congreso, aunque la fecha exacta del cónclave aún estaba por definirse, cambiándose varias veces. El Buró Político del partido soviético decidió el financiamiento del Congreso recién el 7 de octubre (1934), creándose una comisión preparatoria compuesta de 30 integrantes, la mitad los cuales eran latinoamericanos. Dadas las continuas dilaciones del encuentro y la dificultad para cancelar viajes ya planeados de los representantes latinoamericanos, se decidió, finalmente, organizar una Conferencia de partidos de América Latina, a propuesta de Guralsky (Abram Kheifets), en octubre de 1934. También propuso que parte de los delegados que llegarían en octubre, aprovecharan para ir a un curso especial en la Escuela Leninista, mientras esperaban la convocatoria del Congreso ${ }^{7}$. El plan de la conferencia y su agenda fueron discutidos en las reuniones del SLA en Moscú -entre marzo y abril de 1934bajo la presidencia del líder de la IC, Dmitri Manuilsky ${ }^{8}$.

En reunión del 27 de marzo de 1934, intervinieron con ponencias sobre las tareas de la conferencia, Sinani, jefe del SLA (G. Skalov) y su vice, Guralsky. La tesis principal de ambos era una "profecía" sobre las grandes batallas revolucionarios que vendrían en todo el continente, el mismo que, de acuerdo a su convicción, estaba en los umbrales de un nuevo ciclo revolucionario 9 . Ambas ponencias partían de las tesis del informe de Stalin al XVII congreso del PCUS (enero-febrero de 1934) sobre un tipo especial de depresión económica en el mundo capitalista, sobre la crisis revolucionaria y la necesidad de forjar la unidad de los partidos revolucionarios del proletariado como premisa indispensable para que la crisis se trasformara en revolución ${ }^{10}$. En ese momento, en la Comintern, aún predominaba la idea del "asalto" al poder".

El informe de Manuilsky sobre la IC al XVIII Congreso del PCUS, seguía presentando a la social-democracia como el principal responsable de la llegada del fascismo al poder y se la seguía caracterizando como "fascistizante". En el caso de América Latina, según su informe, era el "nacional-reformismo traicionero" ${ }^{12}$ el que obstaculizaba la revolución. De hecho, se mantenían las tesis anti-reformistas del "tercer período".

En la ya mencionada reunión del SLA (de marzo de 1934), Sinani habló de la necesidad de luchar contra el nacional-reformismo, cuya influencia, en su opinión, crecía

\footnotetext{
${ }^{6}$ Drabkin Y.S. La idea de la revolución mundial y su transformación// Historia de la Internacional Comunista, 1919-1943: un ensayo documental. Moscú, Nauka, 2002. P. 67 (en ruso).

${ }^{7}$ Rossiyskiy gosudarsyvenniy arkhiv sozialno-politicheskoy istorii (en adelante RGASPI). Moscow, Russia. $495-79-199$. P. 75.

${ }^{8}$ Yanchuk I.I. En camino hacia el Frente Popular. P. 153.

${ }^{9}$ La Comintern y América Latina. Documentos. Moscú, Nauka, 1998. P. 255 (en ruso).

${ }^{10}$ El XVII Congreso del Partido Comunista de toda la Unión (bolchevique). 26 de enero - 10 de febrero de 1934. El informe estenográfico. Moscú, Partizdat, 1934. P. 12 (en ruso).

${ }^{11}$ Drabkin Y.S. La idea de la revolución mundial. P. 67.

${ }^{12}$ El XVII Congreso del Partido Comunista de toda la Unión (bolchevique). P. 305-310 (en ruso).
} 
en los países del continente. Esta posición estaba en correspondencia con la teoría dominante de la IC sobre la imposibilidad de la burguesía nacional para cumplir un papel revolucionario $^{13}$. Los socialistas latinoamericanos (sobretodo fueron criticados los socialistas argentinos y chilenos, Juan B. Justo y Marmaduke Grove) fueron caracterizados, de acuerdo con el espíritu y letra del "tercer período", como social-fascistas y representantes políticos de la burguesía ${ }^{14}$. Analizando los acontecimientos chilenos de 1932, de la llamada República Socialista y el rol cumplido por el PCCh, la IC impuso la tarea de luchar contra los socialistas (o grovistas), declarando a Grove como "el jefe de una de las pandillas terrateniente-burguesas" $" 15$.

El contenido principal de la ponencia de Sinani no fue la lucha antifascista, y el Frente Único Popular apenas se mencionó, sin que se precisara el concepto, indicándose sólo que, en relación a los países latinoamericanos, ya no se trataba de hacer la revolución socialista, sino la revolución democrática-burguesa, antiimperialista y agraria bajo la hegemonía del proletariado, asunto que, si bien era un cambio respecto del discurso anterior, lo fue sólo en algunos matices. Se mantenía la tarea de crear soviets como órganos de la lucha revolucionaria por el poder, "como órganos técnicos y orgánico-políticos de las masas en su preparación para la sublevación, como órganos futuros de la dictadura democrático-revolucionaria del proletariado y del campesinado", rechazando el concepto de los soviets como los órganos del frente único ${ }^{16}$.

Las reuniones del SLA de marzo-abril de 1934 debían dar forma al programa y agenda de la Tercera Conferencia y elaborar los ejes principales de la discusión. Se debían dar pasos hacia la táctica del Frente Popular, con un paulatino cambio de las tesis del "tercer período" con la finalidad de cambiar los planteamientos obreristas y de la lucha intransigente contra socialdemocracia. La línea divisoria en la táctica, eran las conversaciones de Stalin con el recién electo miembro de la CEIC, Gueorgui Dimitrov, en abril de 1934, intercambio que, en $1^{\circ}$ de julio, lleva a Dimitrov enviar una nota a la comisión preparatoria del VII Congreso, indicando los nuevos objetivos tácticos respecto del frente único y la socialdemocracia ${ }^{17}$.

Después de la reunión de marzo-abril y en vísperas de la conferencia, el SLA envió unas instrucciones "sobre la corrección de errores tácticos". Luego, el 25 de agosto del mismo año, se envió una carta programática en la que hacía un llamado al partido argentino a que se esforzara para formar el frente único con socialistas: comenzándolo por la base, el acuerdo debía luego pasar a un entendimiento con "todo el partido socialista", "apoyándose en la experiencia de los camaradas franceses". En tal carta, se señalaba que el error del período anterior había consistido en "la lucha contra el partido socialista" "18. Por su parte, las mismas indicaciones fueron dadas a los comunistas del Uruguay, criticando su rechazo de colaborar con los socialistas ${ }^{19}$.

\footnotetext{
${ }^{13}$ La Comintern y América Latina. P. 261.

${ }^{14}$ La Comintern y América Latina. P. 270.

${ }^{15}$ La Comintern y América Latina. P. 290.

${ }^{16}$ La Comintern y América Latina. P. 289.

${ }^{17}$ Drabkin Y.S. La idea de la revolución mundial. P. 68.

${ }^{18}$ RGASPI. 495 - 79 - 202. P. 56-57.

${ }^{19}$ RGASPI. 495 - 79 - 202. P. 59.
} 


\section{Sesiones de la Tercera Conferencia y el Frente Único}

La conferencia tuvo lugar en una atmósfera de apasionadas discusiones sobre la táctica a ser adoptada por el VII Congreso. Por un lado, aún no estaban bien claras orientaciones de parte de la dirección de la IC; por otro, fueron poco claras las recomendaciones del XVII Congreso del partido ruso, que continuó profesando las tesis del "tercer período" mientras proponía elaborar un nuevo curso de la Internacional frente a la amenaza del fascismo en Europa, lo que daba gran margen a las interpretaciones. El peso creciente de la influencia de Gueorgui Dimitrov, sobre todo después del proceso de Leipzig $^{20}$, y sus ideas innovadoras, encontraron un suelo fértil en los partidos comunistas de Italia, Francia y de otros países europeos. En su informe, Ghioldi anotó que todos quienes llegaron a Moscú en ese tiempo, observan un claro cambio en la Comintern frente al peligro del fascismo. También subrayó el impacto que en los delegados estaban teniendo las ideas expuestas por Ercoli (Palmiro Togliatti). Reconoció que la mayor parte de los delegados veían aquello con asombro debido a que aun no se entendía cómo interpretar los cambios tácticos en la medida que muchos de los delegados seguían siendo muy sectarios ${ }^{21}$.

Los delegados a la Tercera Conferencia se reunieron del 16 a 28 de octubre de 1934. Eran 23 representantes de los partidos latinoamericanos, fueron acompañados por los funcionarios de la Comintern, de la Internacional Sindical Roja (Profintern), de la Internacional de la Juventud (KIM), además de los delegados de los estudiantes latinoamericanos y profesores de la Escuela Internacional Lenin de Moscú. Entre los funcionarios de la IC expertos en asuntos latinoamericanos, destacaban S. Pestkovsky, V. Miroshevsky, M. Khaskin, A. Guralsky, I. Tulchinskaya, G. Yakobson, Z. Rabinovich, G. Skalov (Sinani) ${ }^{22}$. Como ya se ha dicho, la Conferencia se celebró en un momento clave del viraje de la política de la IC. Aún en septiembre de 1934, las recomendaciones del Comité Ejecutivo (CEIC) al XII Congreso del Partido comunista austriaco y al PC de España, conservaban la letra y espíritu del "tercer período"; pero ya las resoluciones de octubre sobre la cuestión francesa y sobre el «peligro fascista» en Finlandia, tuvieron nuevos matices. La agenda de las discusiones en la Conferencia abarcó los siguientes temas:

- carácter del momento y tareas revolucionarias, el carácter de la revolución;

- frente único y aliados;

- fascismo y coyuntura internacional;

- cuestión brasileña;

- situación en Cuba;

- cuestión agraria;

- problema nacional.

\footnotetext{
${ }^{20}$ Proceso de acusación contra los comunistas culpándolos en el incendio de Reichstag en 1933. Dimitrov fue absuelto y expulsado de Alemania a la URSS.

${ }^{21}$ RGASPI. $495-101-22$. P. 37.

22 Jefets L.S., Jeifets L.S. La izquierda latinoamericana en camino hacia el Frente Popular. P. 62.
} 
El informe principal fue elaborado por Ghioldi (Altobeli), pero igualmente importantes fueron las ponencias del jefe del Secretariado latinoamericano (SLA) Sinani, y su vice, Guralsky, como también las palabras de clausura de Dmitri Manuilsky ${ }^{23}$. El investigador en historia cominterniana, Y. Drabkin, resaltó la actitud vacilante de Manuilsky $^{24}$, quien, si bien se manifestó partidario del frente único como instrumento para que los partidos comunistas conquistasen el control del movimiento obrero, no fue más allá de esto.

La tesis central del informe de Ghioldi seguía los postulados del "tercer período", sobre todo en cuanto al advenimiento de la época del asalto revolucionario al poder y la preparación de las masas a este fin. En efecto, en los materiales preparativos del informe de Ghioldi que se conservan en el archivo de la IC, se remarca la tarea de conquistar la consciencia de las masas para la "idea soviética" ${ }^{25}$, llenando su discurso con citas y referencias del VI Congreso, justificando así las posturas sectarias en relación a las alianzas políticas, aceptables solamente bajo la "hegemonía del proletariado" en lucha contra los partidos reformistas y pequeño burguesas ${ }^{26}$. En estos mismos materiales, vemos que el dirigente argentino se proponía hablar sobre los errores de la Primera Conferencia de los Partidos Comunistas de América Latina y de los representantes de los PC de la región en el VI Congreso, con relación al carácter de la revolución en el continente. Quiso criticar las posiciones de Jules Humbert-Droz, oponiéndole las tesis sobre la revolución democráticoburguesa bajo la hegemonía del proletariado en vistas a su transformación en revolución socialista $^{27}$. Sin embargo, finalmente no habló sobre estos asuntos y abordó principalmente los problemas de la lucha contra el fascismo, de los posibles aliados y del frente único, e invitó a los delegados a discutir las cuestiones agraria y nacional.

Por su parte, en su intervención del 20 de octubre, Sinani inició su exposición con las mismas palabras de la ponencia que hizo en la reunión de marzo, hablando del auge revolucionario y el acercamiento a una crisis revolucionaria en los países del continente. Clausuró su intervención con una sentencia: "En América del Sur y el Caribe estamos como nunca muy cerca de la revolución" ${ }^{28}$. Como prueba de esta tesis mencionó la sublevación de la armada en Chile y la "más grande insurrección campesina en Bolivia", a la cual podían sumarse varios destacamentos militares: "esta sublevación puede llevar a las luchas inmediatas por el poder".

Sobre esta visión de Bolivia, no podemos sino sorprendernos de las fantasías que habitaban en el SLA, y del tipo de información con que se nutrían los jefes de la IC, puesto que nada semejante sucedía en aquel país (la última sublevación campesina importante había sido la de Chayanta, en 1927, que tuvo un carácter local). Sus opiniones preveían de la creación, en Perú y Bolivia, de focos revolucionarios semejantes a los de China ${ }^{29}$, en torno a los cuales Sinani mencionó que correspondían a la etapa democrático-burguesa de

\footnotetext{
${ }^{23}$ Líder informal de la IC, era secretario de la CEIC, representando el Partido soviético en la IC

${ }^{24}$ Drabkin Y.S. La idea de la revolución mundial. P. 69.

${ }^{25}$ RGASPI. 495 - 79 - 198. P. 4.

${ }^{26}$ RGASPI. 495 - 101 - 22. P. 35.

${ }^{27}$ RGASPI. 495 - 79 - 198. P. 4.

${ }^{28}$ La Comintern y América Latina. P. 254.

${ }^{29}$ La Comintern y América Latina. P. 226-227.
} 
la revolución, lo que, de algún modo, podía habilitar otra actitud frente a posibles alianzas con el nacional-reformismo ${ }^{30}$.

En su informe central, Ghioldi subrayó el deseo de las masas -incluyendo las organizadas en los partidos burgueses y reformistas- de emprender acciones conjuntas con los comunistas, dada la crisis general que vivía el mundo capitalista ${ }^{31}$, concluyendo que la idea que podía unir a todas estas fuerzas, era la defensa de la democracia: "El hecho que nosotros desenmascaremos la democracia burguesa como forma de la dictadura de la clase dominante, y que nuestro objetivo sea la dictadura revolucionario-democrática de los obreros y campesinos, a veces nos lleva de presentarnos ante las masas como enemigos de las libertades democráticas, y que la defensa de la democracia es el trabajo solamente de los socialistas y los radicales. Es un gran error. Debemos movilizar a las masas a la defensa de las libertades democráticas. Y si queremos conquistar a las masas para la lucha contra el fascismo, debemos hacer una brusco viraje en nuestra política"32.

No obstante, la defensa de la democracia y la nueva táctica de alianzas y de frente único seguían siendo vistas como vías para conquistar la hegemonía comunista en el movimiento obrero. Más claramente que en la preparación de la ponencia, fue en su alocución misma cuando formuló las bases del frente único: propuso limitarse a la lucha por la unidad de la clase obrera y la formación del frente único a base únicamente de partidos obreros, socialistas y anarcosindicalistas ${ }^{33}$. No todos estaban convencidos, empero, del peligro fascista en América Latina.

Guralsky sostenía que, en los países de la región, el peligro principal consistía, en realidad, en la fascistización de las fuerzas nacional-reformistas ya que en el nacionalreformismo regional, había elementos revolucionarios y fascistas, al mismo tiempo ${ }^{34}$. Esta tesis fue apoyada por el peruano Eudocio Ravines, quien indicó que dentro del movimiento nacional-reformista había corrientes nacional-fascistas, reformistas y revolucionarias, lo que claramente se manifestó en los acontecimientos de Cuba, Chile y Perú ${ }^{35}$. En este marco, la conferencia recomendó realizar una política más flexible con relación a la Alianza Revolucionaria Popular Americana (APRA) liderada por Víctor Raúl Haya de la Torre.

Ghioldi criticó también las ideas "incorrectas" sobre el carácter de la revolución en América Latina: "Nosotros debemos entender que la primera etapa de la revolución antifeudal y antiimperialista consiste en la destrucción de todo el control de los terratenientes, de las supervivencias precapitalistas, la solución más radical de todas las cuestiones de la revolución agraria, de la expulsión de los imperialistas y el no reconocimiento de las deudas externas. A base de eso y bajo la dirección del proletariado, pueden ser creadas las condiciones para una rápida transformación hacia una fase superior. Eso depende del rol dirigente del proletariado, de la fuerza del partido y de las condiciones internacionales etc. En general, se puede decir que hay posibilidades de transformación de

\footnotetext{
${ }^{30}$ La Comintern y América Latina. P. 230.

${ }^{31}$ RGASPI. $495-101-22$. P. 38.

${ }^{32}$ RGASPI. 495 - 101 - 22. P. 39.

${ }^{33}$ RGASPI. 495 - 79 - 198. P. 5.

${ }^{34}$ RGASPI. 495 - 101 - 22. P. 295-301.

${ }^{35}$ RGASPI. 495 - 79 - 213. P. 87-89.
} 
la revolución democrático-burguesa en socialista, y este proceso va a durar relativamente poco tiempo" 36 .

Ravines indicó que el partido argentino debía tomar como ejemplo de su política para con la Unión Cívica Radical (UCR), la táctica de los bolcheviques hacia Kerensky en febrero-octubre de 1917, o sea, la tarea de transformación de la revolución en socialista. Ravines apoyó la táctica de formación de soviets en Chile durante la sublevación de la Armada y la efímera "república socialista" del 1932, y criticó la indecisión del partido chileno. La misma tesis se planteó para Cuba que, al igual que Chile y Brasil, era caracterizada como uno de los "eslabones más frágiles" del sistema capitalista en la región. En la elaboración de la táctica, Ravines llamó a mirar no solamente la historia de la revolución rusa, sino la experiencia china y crear zonas soviéticas ${ }^{37}$. La formación de soviets seguía siendo la consigna más atractiva para los representantes de los PC latinoamericanos.

Otro residuo del "Tercer período" era la tesis de Sinani y Ghioldi sobre el proceso (inconcluso) de bolchevización de los partidos del continente, lo que seguía siendo tarea primordial para los directivos comunistas en sus países ${ }^{38}$. Mientras Ghioldi continuaba con la "proletarización" de los partidos y la lucha contra los "desviaciones", 39 Ravines propuso revisar algunas posturas sectarias de la bolchevización, aunque manteniendo siempre la lucha intransigente contra el trotskismo.

La bolchevización de los partidos peruano y chileno incluía la campaña contra el "mariateguismo" y el "recabarrenismo". Ravines era uno de los primeros en el aparato de la IC en hacer un llamado para revisar esta línea: "Los obreros aprecian mucho a Mariátegui. Los obreros no quieren luchar contra el mariateguismo (...) es cierto que Mariátegui sobreestimó el rol de la burguesía, apoyándose en las palabras de Marx sobre Alemania del siglo XIX, pero luego él mismo reconoció sus errores”. Para los chilenos, Recabarren era una figura revolucionaria emblemática: "En Chile se han cometido muchos errores en el empeño de luchar contra el recabarrenismo. Recabarren tuvo errores, pero no podemos cortar su figura de la historia de la lucha revolucionaria de Chile" ${ }^{40}$. La intervención de Ravines en la conferencia, dio inicio al cambio de actitud hacia Mariátegui y Recabarren en las direcciones de los PC, recuperando sus figuras y su legado. Esto contribuyó al diálogo de los comunistas con otros grupos de izquierda en Perú y Chile. Sobre todo, en el caso chileno, esto permitió comenzar a salir del enclaustramiento sectario de los años anteriores.

Pero Sinani no se limitó a repetir las tesis del "tercer período"; al contrario, alertó a todos los delegados para "estar prevenidos para un viraje brusco que tal vez parezca inesperado en la táctica". Y agregó: "Eso significa que nosotros debemos saber cambiar rápidamente y acomodar nuestras consignas a nuevas circunstancias" ${ }^{41}$. Pero la IC aún no elaboraba una nueva línea, lo que será expuesto solamente más tarde, en su VII Congreso.

Este mismo dirigente también se concentró en la "nueva" interpretación del "más

\footnotetext{
${ }^{36}$ RGASPI. 495 - $101-22$. P. 22-23.

${ }^{37}$ RGASPI. 495 - 79 - 213. P. 90-93.

${ }^{38}$ La Comintern y América Latina. P. 228; RGASPI. 495 - 101 - 22. P. 61.

${ }^{39}$ RGASPI. 495 - 79 - 198. P. 5.

${ }^{40}$ RGASPI. 495 - 79 - 213. P. 420-421.

${ }^{41}$ La Comintern y América Latina. P. 227.
} 
amplio frente único", pero sin salir de los marcos de "la lucha por la mayoría de la clase obrera (...) utilizando esta táctica críticamente en la lucha por nuestros aliados, por los campesinos y las más amplias masas de la pequeña burguesía urbana”. A pesar de anunciar esta novedad en la interpretación del frente único, advertía sobre el peligro inminente de desvíos derechistas cuando esta táctica del frente único se transforma en "entreguismo y conciliación con partidos burgueses y pequeño burgueses" ${ }^{42}$. En su interpretación, la idea frentista tenía pocas diferencias respecto de las posturas del "tercer período". La novedad consistía en el cambio de actitud hacia los socialistas o socialdemócratas: a diferencia de lo que sostenía en sus tesis de la reunión del SLA en marzo de 1934, ahora Sinani no reconocía como error el concepto mismo del social-fascismo, sino su aplicación mecánica en los países latinoamericanos ${ }^{43}$.

La lucha por el cambio socialista seguía siendo la tarea estratégica de los partidos, y Sinani indicó: "En el proceso de la revolución socialista, luchando contra el capitalismo, siempre pensando en su destrucción, nuestro golpe principal debe estar dirigido contra la social-democracia y social-fascismo" "44. A pesar de los cambios propuestos en su ponencia, Sinani no se atrevía a romper con los dogmas del "tercer período", encontrando una justificación de su postura en las citas de los informes de Stalin y de Manuilsky en el XVII congreso del partido ruso. De este modo, la ponencia principal de Sinani en la Tercera Conferencia mantuvo el sectarismo del "tercer período", si bien las recomendaciones concretas, elaboradas en el curso de la Conferencia, reflejaron un leve cambio hacia la táctica del Frente Popular.

Ghioldi, por su parte, subrayó la necesidad primaria de conquista de la unidad de la clase obrera como base del frente único. El argentino llamó al diálogo con socialistas, anarquistas y otros partidos de izquierda. Como ejemplo de los errores del pasado, presentó el comportamiento comunista durante el congreso continental anti-guerra: entonces se consiguió un consenso con los socialistas, pero estos estaban de acuerdo en formar parte del comité anti-guerra bajo la condición de que se invitara también a los representantes del comité ejecutivo del Partido Socialista. "Y como hemos respondido? Que nunca vamos a invitar los directivos del Partido Socialista... Nuestra posición era sectaria. No conseguimos aprovechar las condiciones ventajosas para organizar las más amplias acciones de masas contra el peligro de guerra, prefiriendo utilizar el congreso para ajustar cuentas con los socialistas y anarquistas" ${ }^{45}$. No obstante, Ghioldi continuó interpretando el frente único desde las posiciones del "tercer período" como un instrumento de la unidad del proletariado bajo la hegemonía comunista. Y esta postura fue enérgicamente apoyada por el líder comunista uruguayo Eugenio Gómez, quien subrayó que la tarea del frente único se reducía exclusivamente como táctica a la unidad sindical bajo el liderazgo comunista ${ }^{46}$.

Tanto Ghioldi como Gómez no impulsaban la alianza con otros partidos de izquierda o reformistas, sino la intensificación de la lucha contra ellos por la influencia

\footnotetext{
${ }^{42}$ La Comintern y América Latina. P. 228-229.

${ }^{43}$ La Comintern y América Latina. P. 231.

${ }^{44}$ La Comintern y América Latina. P. 240.

${ }^{45}$ RGASPI. 495 - $101-22$. P. 43.

${ }^{46}$ RGASPI. 495 - 79 - 213. P. 318.
} 
sobre el proletariado. Esta tesis fue principal en el discurso de clausura de Ghioldi ${ }^{47}$. Pero la diferencia entre su informe de abertura y clausura consistió en que, al final del evento, Ghioldi aceptó la alianza con socialistas, anarquistas $\mathrm{u}$ otros izquierdistas, en un frente único "desde abajo". Ghioldi reconoció que, en los países capitalistas desarrollados, como en Europa, era aceptable el frente único con social-demócratas desde abajo y desde arriba, fortaleciendo la lucha antifascista, pero no era tan evidente para los países latinoamericanos. Se expresó contrario a la "aplicación mecánica" de esta táctica en América Latina ${ }^{48}$. Al mismo tiempo, Ghioldi no podía contradecir la atmósfera reinante en la dirección de la IC de aquel momento, debiendo ceder en algunas cosas. Inclusive reconoció la posibilidad de la alianza desde "arriba" con los partidos nacional-reformistas y pequeño burgueses, pero solamente en situaciones especificas de algunos países, como por ejemplo Cuba o Brasil ${ }^{49}$.

Después de la Conferencia, en mayo de 1935, las posiciones del argentino fueron severamente criticadas por el SLA por sectarias. Como la mayoría de los delegados de la Conferencia, Ghioldi rechazaba la idea del Frente Popular desde "arriba" con las estructuras orgánicas de los partidos pequeño-burgueses y burgueses reformistas. No obstante, cambió su punto de vista después de las decisiones formales del VII Congreso ${ }^{50}$.

La opinión de Ghioldi fue compartida por otro argentino, Rojas ${ }^{51}$, que rechazó rotundamente cualquier colaboración con los radicales ya que estos no podían ser considerados nacional-reformistas. Rojas no se atrevió a discutir las indicaciones del SLA sobre la alianza con los nacional-reformistas, y atacó el problema desde otro ángulo: caracterizó a los radicales como un partido burgués reaccionario ${ }^{52}$. Citando los ejemplos del frente único en Francia y España, Rojas aprobó las alianzas de Frente Popular solamente con los socialistas, pero siempre persiguiendo el objetivo de ganar la hegemonía en el movimiento obrero. Sin embargo, inclusive la unidad con los socialistas no iba mas allá de sus bases, ya que sus líderes rechazaban la alianza con los comunistas. Su idea consistió en que las masas debían obligar a sus líderes aceptar la unidad con los partidos comunistas: "Debemos ir a la unificación de las organizaciones de base de los socialistas y comunistas, apoyando las reivindicaciones inmediatas de bases socialistas" 53 .

Los delegados mexicanos (T. Jilme, Aroyo ${ }^{54}$ ) hablaron sobre el frente único exclusivamente en el campo sindical, y subrayaron que, en algunos lugares de su país, ya lo habían logrado 55 . Consideraron como prioridad el frente único "desde abajo"56. Octavio Brandao mencionó que, en las conversaciones del SLA con los delegados mexicanos, se discutió el tema del frente único, no solamente en los sindicatos, sino en relación a las

\footnotetext{
${ }^{47}$ RGASPI. 495 - $101-23$. P. 166.

${ }^{48}$ RGASPI. 495 - $101-23$. P. 172.

${ }^{49}$ RGASPI. 495 - $101-23$. P. 174.

${ }^{50}$ La Comintern y América Latina. P. 300-301.

51 Desconocemos su nombre real. Era miembro de la comisión de credenciales de la 3-ra conferencia

${ }^{52}$ RGASPI. 495 - 79 - 213. P. 341-342.

${ }^{53}$ RGASPI. 495 - 79 - 214. P. 111.

${ }^{54}$ Aroyo, Oroyo u Oroe - desconocemos su nombre verdadero

${ }^{55}$ RGASPI. 495 - 79 - 213. P. 156-159, 297-299.

${ }^{56}$ RGASPI. 495 - 79 - 213. P. 160-163.
} 
células de base del partido gobernante, el Partido Nacional Revolucionario (PNR). Brandao subrayó que el frente único era un instrumento muy útil para desenmascarar los líderes del PNR, más eficiente "que gritar en el periódico El Machete que son traidores y demagogos" predominante. Observando que la política de Frente Popular como alianza desde "arriba" y "abajo" cada día ganaba mas partidarios en Moscú, el uruguayo Gómez expresó su confusión al respecto y solicitó a la CIEC las indicaciones exactas sobre la táctica comunista $^{58}$.

Pocas voces en la Conferencia se expresaron a favor del Frente Popular amplio, como por ejemplo, el uruguayo Oscar Magnin (Oliver), que propuso ampliar la idea del frente único desde abajo e incluir en este a los miembros y las organizaciones de base de los partidos burgueses reformistas que tenían fuerte influencia entre la clase obrera, como radicales en Argentina, socialistas en Chile, batllistas en Uruguay, y apoyar las acciones de estos partidos, pero excluyendo la alianza con sus líderes por ser estos una pandilla burguesa-terrateniente ${ }^{59}$.

Entre los entusiastas de la interpretación más amplia del Frente Popular estaban, además de los uruguayos Martínez (Julio Baccino) ${ }^{60}$ y Magnin, el representante de la Juventud Comunista de Cuba, José Monpie (Wilfredo Velázquez Cabrera), quien contó que Antonio Guiteras ${ }^{61}$ negoció con el Buró político del PC la creación del Frente Popular, pero los comunistas no reaccionaron. Monpie estaba convencido de que, si hubieran podido crear este frente, habría sido más fácil "poner en la agenda del gobierno de Grau ${ }^{62}$ la cuestión sobre la tierra y sobre el armamento del proletariado". Monpie criticó a su partido por su incapacidad para crear el frente único, cerrándose en su política sectaria ${ }^{63}$.

El Frente Popular fue analizado en la Conferencia como una alianza desde abajo con los grupos no-comunistas de la clase obrera y de la pequeña burguesía sin entrar en ningún trato con los líderes reformistas y burgueses. Lo articuló muy claramente el funcionario del SLA brasileño Octavio Brandao: "El frente único tiene dos caras - una, la conquista de las masas quitándoles la influencia de los líderes reformistas, anarco-sindicalistas, pequeño burgueses y burgueses, y otra, desenmascarar a los líderes burgueses, reformistas, a los traidores de las masas. Nunca podemos ofrecer el frente común a los partidos burguésterratenientes" ${ }^{64}$. En cuanto al concepto del frente popular desde arriba, Sinani solamente lo mencionó una vez: "Ahora debemos realizar la táctica del frente único (en relación a la social-democracia) tanto desde abajo, como desde arriba", pero no se aceptaba la alianza desde arriba ni siquiera con las fracciones de izquierda de los partidos pequeñoburgueses y burgueses $^{65}$.

\footnotetext{
${ }^{57}$ RGASPI. 495 - $79-213$. P. 371.

${ }^{58}$ RGASPI. 495 - $79-213$. P. 323.

${ }^{59}$ RGASPI. 495 - $101-22$. P. 74.

${ }^{60}$ Socialista en el pasado.

${ }^{61}$ Fundador de la "Joven Cuba"

${ }^{62}$ Ramón Grau San Martin, presidente de Cuba, líder del partido de los auténticos.

${ }^{63}$ RGASPI. 495 - 79 - 213. P. 336-337.

${ }^{64}$ RGASPI. 495 - 79 - 213. P. 370.

${ }^{65}$ La Comintern y América Latina. P. 253.
} 
Respecto de las organizaciones del SRI (Socorro Rojo Internacional) en América Latina, la Conferencia acordó que tenían que actuar como parte de la estrategia del Frente Popular, proponiéndose su utilización como fachada comunista con su agenda general democrática y antiguerra ${ }^{66}$. Al mismo tiempo, el SRI debía dejar de ser, a los ojos de la opinión pública, una sección de la IC, convirtiéndose en instancia de diferentes partidos y grupos. También, debía cambiar su estilo y retórica para que no estuviera asociado directamente con los partidos comunistas. El SRI, a fin de cuentas, podía ser un instrumento eficiente para el frente único ${ }^{67}$.

Otro tema revisado desde las perspectivas del frente único ampliado, fue la cuestión agraria. En esta materia, se destacó el informe de Ravines quien defendió la idea de incluir en el frente a todos los campesinos, incluyendo a los acomodados o, en términos de la IC y de la realidad rusa, de los kulaks, lo que era una herejía increíble después de la derrota de los bujarinistas en la URSS. El brasileño Brandao también elogió al partido cubano por su apoyo a las acciones de los campesinos ricos contra los plantadores y compañías agrarias extranjeras en la isla, pero criticó a Ravines por su propuesta de incluirlos en el frente único ${ }^{68}$.

Ravines propuso revisar parcialmente las críticas comunistas a las ideas de Mariátegui sobre la cuestión agraria en los países andinos: “¿Cual es la base de la revolución? Para Mariátegui era la comunidad. La comunidad es base de la revolución democrático-burguesa en el campo, y no puede ser la base de la revolución socialista. Mariátegui no contempló el paso de la comunidad y de todo el campesinado a la revolución socialista, desarrollando la lucha de clases en el agro, lo que es inevitable en el paso a la revolución socialista" ${ }^{69}$. Ravines subrayó que la crisis venidera tenía rasgos especiales, ya que en varios sectores disminuía el desempleo y el proletariado no iba a participar de las luchas revolucionarias. De este modo, el campo se convertiría en el centro de la revolución, mientras que el mayor problema de los comunistas era su frágil influencia entre los campesinos $^{70}$.

\section{Cuestiones especiales: Brasil y Cuba}

En marzo de 1934 en Moscú se creó la Comisión Permanente de América del Sur y del Caribe, compuesta por altos funcionarios de la IC: Dmitri Manuilsky, Solomon Lozovsky, Wilhelm Knorin (Tischler), Boris Vasiliev, Abram Guralsky, Gueorgui Skalov (Sinani). En esta comisión, casi el único tema fue la cuestión brasileña, es decir, los preparativos y la coordinación de la revolución en Brasil ${ }^{71}$. Las situaciones de este país sudamericano y de Cuba, atrajeron la atención en la Tercera Conferencia. Chile también fue mencionado, pero la situación chilena no fue revisada por los delegados en la sesiones

\footnotetext{
${ }^{66}$ RGASPI. $495-79-202$. P. 59.

${ }^{67}$ RGASPI. 495 - 79 - 198. P. 64-67.

${ }^{68}$ RGASPI. 495 - 79 - 213. P. 372-376.

${ }^{69}$ RGASPI. 495 - $79-213$. P. 422.

${ }^{70}$ RGASPI. 495 - 79 - 213. P. 86.

71 Jeifets L.S., Jeifets L.S. La izquierda latinoamericana en camino hacia el Frente Popular. P. 63.
} 
especiales $^{72}$.

Para Cuba el Frente Popular amplio se recomendaba en forma de frente anti intervencionista (antiimperialista) con la participación de los partidos democráticoburgueses, incluyendo el Auténtico, de Ramón Grau San Martin. Esta consigna fue apoyada por Ghioldi después de superadas vacilaciones y dudas que, en los comienzos, lo hizo mantener una posición más cerrada y sectaria. Recién en su discurso de clausura Ghioldi lo apoyó, pero poniendo el acento en que había que hacer hincapié en el frente desde "abajo", y buscar aliados solamente en las fracciones izquierdistas de estos partidos ${ }^{73}$.

En la resolución especial sobre Cuba, el Partido Auténtico fue caracterizado como nacional-reformista y el grupo de Guiteras (Joven Cuba), como nacional-revolucionario, y ambos fueron considerados como posibles aliados de los comunistas para formar el Frente Popular. Sin embargo, en Cuba, en esas fechas, se reunió el pleno de CC del PC, manteniendo los viejos moldes, tratando a los Auténticos de fascistas ${ }^{74}$.

La "resolución cubana" de la Conferencia criticó al PC de Cuba por su postura sectaria, por el rechazo a apoyar a las fuerzas reformistas encabezada por Grau San Martín, por no saber diferenciar las fuerzas contrarrevolucionarias del partido $\mathrm{ABC}$, de las fuerzas pequeño burgueses, nacional-reformistas (Grau) y nacional-revolucionarias (Guiteras). Sostenía, por el contrario, que se debía formar una amplia política y aplicar "la táctica del frente único como medio de movilización del pueblo oprimido de Cuba" ${ }^{75}$. La resolución tuvo un serio impacto en la política del PC cubano, que cambió su actitud hacia los posibles aliados: Auténticos y Joven Cuba. En 1935, el PC propuso crear el frente único antiimperialista, junto con el Directorio Estudiantil, pero bajo el liderazgo de los comunistas. Y solamente en mayo de 1936, después del VII Congreso, los comunistas cubanos comenzaron a realizar la política de Frente Popular.

Pero más tiempo que el dedicado a la situación cubana, fue el empleado en la Conferencia para ver los asuntos relacionados con la crisis política brasileña. Resultado de la discusión, se aprobó una resolución especial. Ya ntes de la Tercera Conferencia, Brasil estuvo en el centro de la atención de la IC: en abril-mayo de 1934, uno de los asuntos más discutidos en las reuniones del SLA - con presencia de Manuilsky- fue la preparación de la sublevación armada en Brasil y el envío de los emisarios de la IC a ese país ${ }^{76}$. En enero de 1934 fue enviado a Moscú un informe de SSA que notó la debilidad del partido brasileño y su incapacidad para cumplir las decisiones de la Comintern, no haciéndose ninguna mención a la situación prerrevolucionaria en Brasil, o de la eventual posibilidad de algún movimiento armado bajo el liderazgo comunista ${ }^{77}$.

El jefe del SLA, Sinani, quien en la década de 1920 pasó varios años en China como

\footnotetext{
${ }^{72}$ Chile fue representado por Ravines. Aunque Contreras Labarca está en la lista de los delegados, por lo visto no estuvo, ya que no hay ninguna intervención de él. Ghioldi, en su discurso de clausura de la Conferencia, dijo: «Lamentablemente aquí no hay representantes de Chile para presentarnos un cuadro del movimiento de masas en este país»-RGASPI. 495 - 101 - 23. P. 178.

${ }^{73}$ RGASPI. 495 - $101-23$. P. 179.

${ }^{74}$ RGASPI. 495 - 79 - 225. P. 8-9.

${ }^{75}$ RGASPI. 495 - 101 - 25. P. 80.

${ }^{76}$ Yanchuk I.I. En camino hacia el Frente Popular. P. 153.

${ }^{77}$ RGASPI. 495 - 79 - 202. P. 5.
} 
el asesor militar ${ }^{78}$, fue partidario de aplicar la experiencia china en los países latinoamericanos. Para él, Brasil era una "China latinoamericana" por su tamaño y por su estructura. Para la preparación de los cuadros brasileños fue creado (1935) un grupo especial de estudio de la experiencia china en la Escuela Internacional Lenin ${ }^{79}$. Cuando en tal año Sinani fue investigado por acusaciones de trotskismo (luego, apresado), una de las "pruebas" de su filiación trotskista era su idea de aplicar la experiencia china en Brasil. Entonces declaró al interrogador que esta política fue apoyada por Manuilsky, o sea, por uno de los jefes máximos de la CEIC $^{80}$.

En la Conferencia, los participantes en la discusión no dejaron de señalar que Brasil estaba en los umbrales de la revolución y, por eso, había que buscar todas las alianzas políticas posibles, inclusive con partidos pequeño-burgueses y burgueses. Únicamente Octavio Brandao, quien entonces trabajaba en el SLA, estaba categóricamente en contra de tales alianzas ${ }^{81}$.

La idea de la sublevación fue apoyada por la nueva dirección del partido brasileño en Moscú, donde, en ese momento, también se encontraba Luis Carlos Prestes. Según los datos del mismo PCB, en vísperas del VII Congreso, militaban en la organización unos 5.000 miembros, siendo superados solo por el partido argentino ${ }^{82}$. Según relato posterior de Prestes, la información demasiado optimista sobre las perspectivas revolucionarias del PCB fue dada por el secretario general de entonces, Miranda (Antonio Maciel Bonfim), informes eran puras fantasías, reportando sobre las células del PC que nunca existieron ${ }^{83}$. En realidad, estas incriminaciones contra Miranda fueron hechas después del fracaso de la sublevación comunista en noviembre de 1935, cuando se buscaba un chivo expiatorio ${ }^{84}$.

La IC pensó la revolución brasileña como el inicio de una revolución soviética continental y, según Manuilsky, sería incluso un impulso para una explosión revolucionaria de los negros en EEUU. Además, la revolución brasileña sería una contribución importante para la lucha del proletariado mundial en el marco de "agudización de las contradicciones interimperialistas" entre EEUU y Inglaterra ${ }^{85}$. Manuilsky sostuvo que la debilidad del Estado brasileño (sobre todo, en el interior del país) creaba las premisas para la formación de las regiones soviéticas según el ejemplo chino, pero la resolución de la Conferencia prefirió apostar por un rápido asalto al poder y recomendó concentrar los esfuerzos del PC en Pernambuco, San Pablo y Río de Janeiro, donde se concentraba el proletariado brasileño

\footnotetext{
${ }^{78}$ Su seudónimo - Sinani - proviene de la palabra China.

79 Jeifets V., Jeifets L. La Comintern y la formación de militantes comunistas latinoamericanos // Izquierdas, No. 31, diciembre 2016. P. 142.

${ }^{80}$ Jefets L.S., Jeifets L.S. La izquierda latinoamericana en camino hacia el Frente Popular. P. 65.

${ }^{81}$ RGASPI. 495 - 79 - 213. P. 370.

${ }^{82}$ RGASPI. 495 - 17 - 9. P. 29-30. En el informe de Marques (Barbosa Loureiro) al VII Congreso de la IC, figuran otros datos: para julio de 1934, de 8 a 10 mil miembros. - RGASPI. 495 - 29 - 78. P. 53.

${ }^{83}$ Koval B. La tragedia heroica del XX: la vida de Luis Carlos Prestes. Moscú, Nauka, 2005. P. 153 (en ruso).

${ }^{84}$ Antonio Maciel Bonfim era secretario general del PC brasileño en 1934-1936. Aceptado en el partido a través de la organización prestista LAR, despues de haber cortado el con propio Prestes. Subió rápidamente en la jerarquia del partido gracias a su origen proletario, cumpliendo los términos de la bolchevización impuesta por la IC. Capítulos de história dos comunistas no Brasil. P. 82.

85 3-ra conferencia de los partidos comunistas de América del Sur y del Caribe. P. 167-168.
} 
y estaban las condiciones para la revolución ${ }^{86}$.

Aunque en la IC destacaban "las lecciones" de la revolución china ${ }^{87}$, Prestes estaba en contra de repetir esa experiencia en Brasil, en especial la táctica de la alianza del PC con el nacional-reformismo del Koumintang, ya que temía la pérdida de independencia del partido y el aislamiento de su núcleo revolucionario. Él defendió la idea del liderazgo comunista en una alianza inter-partidaria e interclasista ${ }^{88}$.

Los delegados brasileños estuvieron menos entusiasmados con las perspectivas de la revolución que imaginaban los jefes cominternianos. El propio Miranda reconoció la debilidad del partido, aunque tuvo que aceptar la idea dominante de que la revolución era inevitable (Miranda siempre decía en Moscú lo que allí querían escuchar): "la revolución brasileña llegará con nosotros o sin nosotros, bajo nuestro liderazgo o sin él" ${ }^{89}$. Los brasileños insistían que aún faltaba mucho para lograr la hegemonía en la clase obrera y convertir al partido en una organización de masas ${ }^{90}$.

Los delegados brasileños no contradecían a sus camaradas de la IC sobre que la revolución en su país iba a ser de "tipo ruso" 91 . De hecho, en sus informes, seguían el "esquema ruso" de transformación de la revolución democrático-burguesa en una revolución soviética mediante el Frente Popular: la revolución antifeudal y antiimperialista podía ser exitosa solamente con "la creación del gobierno soviético obrero-campesino" 92 . Pero dado que la revolución sería agraria y que el PC carecía de posiciones fuertes en el campo, lo único con que podían contar, era con la confianza de las campesinos en Prestes ${ }^{93}$.

Contemplando la situación en el campo brasileño, los funcionarios de la SLA (como Vladimir Miroshevsky), consideraron que los bandoleros tradicionales del nordeste, los cangaceiros, podían ser aliados naturales de la revolución. Miroshevsky supuso incluso que en la revolución brasileña, el líder de los cangaceiros de Pernambuco, de apellido Lampeão, "podría ser un excelente jefe del Estado Mayor del ejercito rojo de nordeste de Brasil" "94. Y más adelante sostenía: "Solamente basta ponerle al lado de él un comisario, y veremos a Lampeão entre nosotros, aquí, en la próxima conferencia" ${ }^{95}$. Obviamente, se trataba de un absurdo. El propio Prestes, que escuchaba estas fantasías, debía recordar como los terratenientes usaban a los cangaceiros contra su columna en los años 20. Los delegados brasileños (Almeida y J. Machado) reconocían que los integralistas (fascistas brasileños) tenían más presencia en el campo que los comunistas ${ }^{96}$.

Pocos meses después de la Tercera Conferencia, el 13 de febrero de 1935, la IC aprobó una resolución sobre la situación brasileña en la que se admitía que el partido brasileño aun era muy débil, carecía de influencia en las masas. Ante ello, sin embargo, el

\footnotetext{
${ }^{86}$ RGASPI. $495-29-80$. P. 12.

${ }^{87}$ RGASPI. $495-78$ - 78. P. 14.

${ }^{88}$ RGASPI. 495 - 79 - 213. P. 230.

89 3-ra conferencia de los Partidos Comunistas de América del Sur y del Caribe. P. 178.

${ }^{90}$ RGASPI. 495 - 29 - 78. P. 36-38.

91 3-ra conferencia de los Partidos Comunistas de América del Sur y del Caribe. P. 177.

${ }^{92}$ RGASPI. 495 - 29 - 78. P. 20-21.

93 3-ra conferencia de los Partidos Comunistas de América del Sur y del Caribe. P. 174-175.

${ }^{94}$ Los delegados respondieron a esta frase con risas.

${ }^{95}$ RGASPI. 495 - 79 - 213. P. 361.

${ }^{96}$ RGASPI. 495 - 79 - 213. P. 291.
} 
PC insistía en la tarea de la lucha inmediata por el poder a través de la táctica del frente único desde arriba y desde abajo: "El Partido y las organizaciones revolucionarias de masas debían realizar acciones conjuntas para formar la unidad real de acción de la clase obrera. Solamente con la táctica cotidiana del frente único en cada fábrica, en cada empresa, hacienda, puede lograr a la mayoría del proletariado al lado de la lucha por las reivindicaciones inmediatas ... PCB debe dirigirse a los partidos socialistas, 'proletarios' u otros, que cuentan con el apoyo de las masas, a los reformistas, anarco-sindicalistas y otros sindicatos, proponiéndoles el frente único electoral ... Con estas propuestas de acciones conjuntas, a base del frente único, hay que dirigirse no solamente a las organizaciones de abajo de tales partidos, como el Socialista, Proletario-Socialista, Proletario del Estado de Río de Janeiro etc., sino también, a las directivas de dichos partidos" 97.

Prestes era partidario de alianzas más amplias para aprovechar las contradicciones en el seno de la burguesía nacional aliándose con sus fracciones reformistas ${ }^{98}$. La IC recomendó mayor flexibilidad táctica del frente único en la esfera sindical inclusive con los sindicatos oficialistas o pro-gubernamentales. Todo el trabajo sindical debía estar subordinado al objetivo estratégico de crear soviets a través de los comités sindicales de base $^{99}$. También se recomendaba flexibilidad en la política eclesiástica: "Actualmente el PCB debe actuar de modo tal que la lucha contra la iglesia no parezca tener el carácter antirreligioso" ${ }^{100}$. El PCB debía prever la lucha del traspaso del poder de las manos del gobierno revolucionario transitorio a la formación de los soviets y al poder obrerocampesino. Pese a la nueva retórica del Frente Popular, Brasil era una excepción donde se aplicaban antiguos postulados políticos sobre una inminente revolución soviética. Y, para el éxito de esta línea, el PC brasileño debía concluir el proceso de "bolchevización", iniciado en el período anterior ${ }^{101}$.

Después que la Conferencia tuvo lugar, se llevó a efecto una reunión "a puerta cerrada" sobre la cuestión brasileña con la participación de los jefes del SLA y algunos delegados especialmente escogidos: Prestes, Ghioldi, el cubano Blas Roca, Ravines, el brasileño Ferreira Lima y los máximos líderes de la IC: Dimitrov y Manuilsky. Dimitrov, quien insistía en la aplicación inmediata del concepto del Frente Popular por todo el mundo, tuvo que ceder a las presiones del aparato de Manuilsky y al ambiente izquierdista de los delegados latinoamericanos que no querían abandonar los viejos modelos del "tercer periodo". Dimitrov aceptó que, a diferencia con otros países del continente donde se debía promover la política del Frente Popular, en Brasil debía centrarse en la sublevación $\operatorname{armada}^{102}$. Según cuenta Ravines, los brasileños encabezados por Prestes mostraban su convicción en el éxito militar y los soviéticos discutían formas de ayuda con armas, incluyendo el envío de barcos y submarinos con armamento. Manuilsky garantizó la ayuda material y financiera para la preparación de sublevación ${ }^{103}$. Unos meses después (13

\footnotetext{
${ }^{97}$ RGASPI. $495-29-80$. P. 3, 5.

${ }^{98}$ RGASPI. 495 - 79 - 213. P. 224-225.

${ }^{99}$ RGASPI. 495 - 29 - 80. P. 16-19.

${ }^{100}$ RGASPI. 495 - 29 - 80. P. 27.

${ }^{101}$ RGASPI. 495 - 29 - 80. P. 6-8.

102 Ravines E. La Gran estafa. P. 256.

103 Ibid. P. 257.
} 
febrero de 1935) fue aprobada y corroborada la resolución sobre Brasil que subrayaba que, aunque el partido siguiera siendo frágil, debía afrontar la tarea de la lucha armada por el poder, aplicando la política del frente único desde arriba y desde abajo ${ }^{104}$.

\section{Secuencias de la Tercera Conferencia}

La Conferencia aprobó varias resoluciones que debían pasar por los directivos de la IC para convertirse en documentos oficiales. Su cuestión central era el frente único y los aliados políticos, lo que provocó serias resistencias entre los líderes de los PC. Ghioldi reconoció que en varios partidos había "una resistencia colosal contra la táctica del frente único" "105 y él mismo seguía haciendo llamados al asalto del poder, y al establecimiento en los países de la región, del "poder soviético como única salida posible" ${ }^{106}$. Si la resistencia "izquierdista" a la nueva táctica de la IC partía, en su mayor parte, de los viejos funcionarios y reconocidos líderes del aparato -como Bela Kun o Knorin, que pertenecían al grupo de Iosif Piatnitsky, que compartieron con éste su suerte durante las represiones staliniana $^{107}$ - en el seno de los partidos comunistas latinoamericanos los más tenaces "izquierdistas" que no aceptaban los cambios fueron los "burócratas" de Buenos Aires y del SSA, cuyo portavoz principal era Ghioldi y otros delegados argentinos ${ }^{108}$.

En su informe, Ghioldi subrayó la lentitud burocrática en aplicar las decisiones de la IC: "Si el partido formula alguna consigna, ésta debe pasar tantas instancias burocráticas que, al llegar a nuestra periferia, ya está desactualizada. Unas consignas desactualizadas andan por pasillos burocráticos unos 8-9 meses, y cuando la correlación de fuerzas ya cambió, la consigna por fin llega a las bases. Ahí está nuestra incapacidad para reaccionar rápidamente a los cambios de las masas" ${ }^{109}$. El SLA en Moscú era objeto de severas críticas de parte de los directivos de la IC. En la Tercera Conferencia, Manuilsky declaró: "El Secretariado Latinoamericano es una entidad muy especial. Es incapaz de reaccionar rápidamente a los acontecimientos - en realidad todos nuestros secretariados son incapaces" 110. La conclusión lógica era bregar por una mayor independencia de los partidos nacionales, pero esta idea no fue apoyada por los funcionarios del SLA, Sinani y Guralsky.

En la dirección de la IC existía descontento y desilusión por el funcionamiento de los órganos regionales de coordinación de los partidos. En marzo de 1935, después de la Tercera Conferencia, Van Min envió una carta a la Comisión política de la CEIC sobre la necesidad de reformar el Buró del Caribe (que tenía su sede en Nueva York) ya que era incapaz de cumplir sus tareas, y de reaccionar efectiva y correctamente a los procesos políticos. El trabajo de A. Bittelman podía ser estimado como satisfactorio, pero después de su cambio por Carlo Codevilla (Moro), el Buró comenzó a cometer serios errores: en contradicción a las resoluciones cubanas de la Tercera Conferencia sobre el frente único

\footnotetext{
${ }^{104}$ RGASPI. $495-29-80$. P. 3, 5.

105 RGASPI. 495 - 101 - 22. P. 37.

${ }^{106}$ RGASPI. 495 - $101-23$. P. 184.

107 Vatlin A. Comintern: ideas, decisiones, destinos. Moscow: ROSSPEN, 2009. P. 355-356. (en ruso)

${ }^{108}$ Izquierda. Crítica y acción socialista. Buenos Aires. No. 7. Agosto-septiembre de 1935. P. 3.

${ }^{109}$ RGASPI. 495 - 101 - 22. P. 38-39.

110 3-ra conferencia de los Partidos Comunistas de América del Sur y del Caribe. P. 164.
} 
con los auténticos y guiterristas, el Buró presionó al Pleno del CC del PC de Cuba para que los caracterizara como fascistizantes ${ }^{111}$. También el Buró cometió errores graves en relación al PC mexicano que, curiosamente, condenó el curso anticlerical y la política de "educación socialista” del gobierno de Lázaro Cárdenas, caracterizándola como "nacionalsocialista, tipo hitleriana".

Como resultado de la carta de Van Min, el 9 de abril de 1935 el jefe del SLA, Kuchumov, le quitó todas las facultades políticas al Buró del Caribe por incumplimiento de las resoluciones de la Tercera Conferencia, manteniéndole solo las funciones técnicas de coordinación hasta una "nueva decisión sobre cambio de los cuadros directivos"112. Esta orden de Kuchumov fue el primer paso en la liquidación del Buró del Caribe.

En virtud de la crítica a la lenta reacción de la IC a los acontecimientos en el subcontinente latinoamericano, después de la Conferencia fueron creadas comisiones especiales para cada país. Sin embargo, en estas comisiones trabajaban los mismos funcionarios de la SLA, por lo que se trataba de una mera solución burocrática al problema. Después del VII Congreso, el SLA fue liquidado, dándosele mayor independencia a los partidos nacionales. Además, la Tercera Conferencia marcó los cambios en la organización sindical comunista, abriendo la posibilidad del trabajo comunista en los sindicatos reformistas. En la Conferencia, Ghioldi había subrayado que los PC habían mostrado ser incapaces de ganar el control en los sindicatos ${ }^{113}$. Sinani propuso apelar a figuras filocomunistas, pero independientes, del movimiento sindical, como el mexicano Lombardo Toledano, lo que parecía un camino adecuado para la política de frente único proletario ${ }^{114}$. Posterior a la Conferencia, en la Profintern tuvo lugar una reunión sindical regional en la cual Ravines, apoyado por Prestes, propuso liquidar el CSLA por haberse convertido en un aparato burocrático sin ninguna influencia en el movimiento sindical real, pasándose a la afiliación directa de los centrales sindicales nacionales a la Profintern ${ }^{115}$. Pero después del VII congreso, tanto el CSLA y como la Profintern fueron disueltos.

Las resoluciones de la Tercera Conferencia quedaron en el olvido. Hasta febrero de 1935, en el SLA se lamentaban de que no hubiera un texto definitivo. Las redactaban, las enviaban para obtener el visto bueno de los órganos superiores de la IC, cambiaban las fórmulas... y eso parecía un trabajo sin fin. Su traducción al español y su publicación ${ }^{116}$ fue prevista para marzo, pero esto nunca sucedió, ya que la IC cambió la agenda y las fórmulas en vísperas del VII Congreso. Claramente, las resoluciones de la Tercera Conferencia latinoamericana habían quedado demasiado anticuadas. Las resoluciones, sin una fórmula clara del Frente Popular, solamente podían desorientar a los partidos. Todo fue archivado y, con eso, la propia memoria sobre la Tercera Conferencia.

El difícil cambio hacia la política de Frente Popular era una paso lógico y consecuente en la larga transformación de la IC a partir del dictado estaliniano de construcción del socialismo en un solo país, de abandono del ideario de la revolución

111 RGASPI. $495-79-225$. P. 8-10

${ }^{112}$ RGASPI. $495-29-81$. P. 56-57.

${ }^{113}$ RGASPI. $495-101-22$. P. 46.

${ }^{114}$ La Comintern y América Latina. P. 246

${ }^{115}$ RGASPI. $534-3-979$.

${ }^{116}$ RGASPI. 495 - 79 - 224. P. 1-2. 
mundial y de sumisión de la estrategia comunista a los intereses de la política exterior de la URSS. La política de Frente Popular fue una culminación de este proceso y, más correctamente, correspondió a los intereses de la política exterior del gobierno soviético ante el inminente peligro de la guerra mundial. De poca importancia fue que muchos de sus aspectos político-ideológicas no fueran aceptados ni comprendidos por los revolucionarios de todo el mundo, ni siquiera por todas las direcciones de los partidos burocratizados en el periodo de la bolchevización. Punto final del impacto de la Revolución bolchevique como inicio de la revolución proletaria mundial y punto de partida de la institucionalización del movimiento comunista en el sistema político internacional del capitalismo. A partir de ahí la consigna principal fue la lucha por la paz internacional y defensa de la URSS, lo que sustituyó las tareas de la revolución socialista mundial. El viraje de la Comintern hacia el Frente Popular fue punto radical que marcó el fin de la existencia del partido mundial de la revolución proletaria, el encierro de los partidos comunistas en sus fronteras nacionales. Tal como lo describió en ese momento Lev Trotsky: "La III Internacional nació de una protesta indignada contra el social-patriotismo. Pero el contenido revolucionario que le había insuflado la Revolución de Octubre se había agotado hace mucho tiempo"117.

Los materiales de la Tercera Conferencia de los partidos latinoamericanos de 1934 claramente demuestran que el viraje hacia el Frente Popular no fue producto de la eclosión interna en el seno de los partidos comunistas nacionales, sino una nueva política elaborada por la directiva máxima del partido soviético y de los nuevos líderes de la IC como Dimitrov, quedando los jefes del aparato latinoamericano de la IC, como Manuilsky, y Sinani, como simples canales de las decisiones de arriba, operadores para maniobrar ante las posibles resistencias de las burocracias comunistas. La Tercera Conferencia demostró tal algoritmo del quehacer político cominterniano. Así, no fue sorprendente que, mientras la nueva línea del Frente Popular redirigía los esfuerzos de los partidos a la política interna, a las negociaciones y alianzas locales -dejando en el pasado las consignas de la revolución proletaria internacional-, al mismo tiempo, minó las bases de existencia de la burocracia cominterniana representada sobre todo por el SSA y los comunistas argentinos. De ahí su mayor resistencia a este viraje, aunque esta fuera encubierta y enmascarada en los discursos de adhesión incondicional a la nueva línea de la IC. La burocracia defendía sus posiciones político-sociales y parece que entendía perfectamente que pronto llegaría la hora de la desaparición de los órganos supranacionales de la IC y, luego, de la propia IC.

\section{Bibliografía}

Fuentes primarias

Tercera conferencia de los partidos comunistas de América del Sur y del Caribe. Documentos. // Latinoamerikanskiy istoricheskiy almanakh. №3. 2002. (en ruso).

${ }^{117}$ Trotsky L. La revolución traicionada. ¿Qué es y a dónde va la URSS? Madrid: Fundación Federico Engels, 2001. P. 154 
XVII Congreso del Partido Comunista de toda la Unión (bolchevique). 26 de enero - 10 de febrero de 1934. El informe estenográfico. Moscú, Partizdat, 1934. (en ruso).

Izquierda. Crítica y acción socialista. Buenos Aires. No. 7. Agosto-septiembre de 1935.

La Comintern y América Latina. Documentos. Moscú, Nauka, 1998. (en ruso).

Rossiyskiy gosudarsyvenniy arkhiv sozialno-politicheskoy istorii (RGASPI). Moscow, Russia.

Trotsky L. La revolución traicionada. ¿Qué es y a dónde va la URSS? Madrid: Fundación Federico Engels, 2001.

Libros - artículos

Capítulos de história dos comunistas no Brasil. / Carlos Zacarias de Sena Júnior, organizador. Salvador da Bahia:EDUFBA, 2016.

Claudin F. La Crisis del movimiento comunista.

http://www.marxistarkiv.se/espanol/komintern/claudin-crisis_del_movimiento_voll.pdf 15.12.17

Drabkin Y.S. La idea de la revolución mundial y su transformación// Historia de la Internacional Comunista, 1919-1943: un ensayo documental. Moscú, Nauka, 2002. (en ruso).

Hobsbawm E. Revolucionarios. Ensayos contemporáneos. Barcelona: Crítica, 2010.

Jeifets L.S., Jeifets L.S. La izquierda latinoamericana en camino hacia el Frente Popular, los años 30 del siglo XX// Latinskaya Amerika. Moscú, ILA RAN. No.5. 2014 (en ruso).

Jeifets V., Jeifets L. La Comintern y la formación de militantes comunistas latinoamericanos // Izquierdas, No. 31, diciembre 2016.

Koval B. La tragedia heroica del XX: la vida de Luis Carlos Prestes. Moscú, Nauka, 2005. (en ruso).

Ravines E. La Gran estafa (La penetración del Kremlin en Iberoamérica). México: Libros y revistas, 1952.

Traverso E. Memoria del futuro. Sobre melancolía de izquierda. // Nueva Sociedad. No. 268. Marzo-abril, 2017.

Vatlin A. Comintern: ideas, decisiones, destinos. Moscow: ROSSPEN, 2009. (en ruso)

Yanchuk I.I. En camino hacia el Frente Popular: 3-ra conferencia de los comunistas latinoamericanos de 1934. // Latinoamerikanskiy istoricheskiy almanakh. Moscú, IVI RAN. №3. 2002 (en ruso). 